\title{
CONTRAFIGURAS DE LA MODERNA MERCANTILIZACIÓN DEL MUNDO. ARISTÓTELES, KARL POLANYI Y EL SUMAK KAWSAY
}

\section{COUNTER-FIGURES OF THE WORLD'S MODERN MERCANTILIZATION. ARISTOTLE, KARL POLANYI AND SUMAK KAWSAY}

\author{
Jorge Polo Blanco" \\ Escuela Superior Politécnica del Litoral \\ Guayaquil, Ecuador
}

\begin{abstract}
Resumen: En el presente trabajo queremos rastrear la lógica economicista y productivista que, en buena medida, definió el desarrollo de la modernidad occidental. Y para ello recurriremos a tres figuras muy distantes entre sí que, sin embargo, nos ofrecen de distinto modo y en diferentes contextos un contrapunto muy nítido a esa misma lógica. En ese sentido, creemos que la filosofía económica de Aristóteles, la intervención crítica de Karl Polanyi y algunos saberes del universo cultural prehispánico vinculados a la noción quichua de Sumak Kawsay, representan tres contrafiguras muy potentes de ese devenir social y espiritual propiciado por el triunfo arrollador de la economía de mercado y de la visión del mundo a ella vinculada. Trataremos de mostrar el hilo conductor que subyace a tres pensamientos tan alejados en el tiempo y en la geografía, toda vez que en ellos encontraremos elementos comunes que pueden ser empleados para construir un dibujo preciso y una crítica fundada de los desmanes de esa lógica economicista y productivista propia de las modernas sociedades de mercado.
\end{abstract}

Palabras clave: Modernidad, mercantilización, Aristóteles, Karl Polanyi, Sumak Kawsay

\footnotetext{
* Escuela Superior Politécnica del Litoral, ESPOL, Escuela de Diseño y Comunicación Visual, Campus Gustavo Galindo Km. 30.5 Vía Perimetral, P.O.Box 09-01-5863, Guayaquil, Ecuador.
} 
АвSTRACT: In this paper, we aim to trace the economic and productivist logic that largely defined the development of Western Modernity. Therefore, we will turn to three figures which, although distant from one another in time, offer us a sharp counterpoint to the same logic through different approaches and in different contexts. In this regard, we believe that the economic philosophy of Aristotle, the critical intervention of Karl Polanyi, and certain forms of knowledge from the Pre-Hispanic cultural universe linked to the Quechuan notion of Sumak Kawsay represent three powerful counter-figures in this social and spiritual evolution brought about by the resounding triumph of the market economy and the vision of the world linked to it. Our aim is to show the common thread that underlies the three schools of thought which are so distant in time and geography, inasmuch as there are common elements running through them that could be deployed to formulate a precise drawing and critique founded on the excesses of this economic and productivist logic that is characteristic of modern market societies.

KeYwords: Modernity, mercantilization, Aristotle, Karl Polanyi, Sumak Kawsay.

\section{Sociedades de mercado: una exoticidad antropológica, una rareza histórica}

El surgimiento de las modernas sociedades de mercado en el siglo XIX europeo fue un proceso histórico esencialmente disruptivo, un acontecimiento que revolucionó y dislocó la textura antropológica de las sociedades humanas en las que irrumpió. Esa nueva institucionalización de lo económico suponía nada menos que una creciente mercantilización de todos los dispositivos sociales previamente no sujetos a la compraventa mercantil, a saber, el dinero, la tierra, la naturaleza y, de forma eminente, el trabajo humano. La tremenda revolución histórico-cultural que supuso edificar este inédito aparato institucional, por medio del cual todos esos elementos empezaron a quedar sujetos de una manera cada vez más integrada en un mecanismo de libre mercado formador de precios, implicó una violenta dislocación social sin precedentes. La vida de la gente común empezó a fraguarse en unos moldes jamás vistos con anterioridad (Polanyi, 1976b). La gran movilización de las fuerzas laborales, a comienzos del siglo XIX, supuso una nueva y violenta codificación de los espacios productivos, pues no debe olvidarse que el trabajo asalariado hubo de ser impuesto a través de múltiples intervenciones y reglamentaciones que regulaban los flujos de aprovisionamiento de mano de obra "libre" (Moulier-Boutang, 2006).

Si un pensador fue capaz de rastrear a fondo los efectos del tal acontecimiento fue el historiador y antropólogo austrohúngaro Karl Polanyi, cuyos potentes 
trabajos al respecto fueron elaborados y publicados en la primera mitad del siglo XX. "En un período extremadamente breve, la ficción mercantil aplicada al trabajo y a la tierra, transformó la esencia misma de la sociedad humana"1. Un poderoso mecanismo institucional, absolutamente inédito en la historia de las civilizaciones humanas, había producido una quiebra brutal en inveteradas maneras de organizar el sustento material de la sociedad; nunca antes sociedad humana alguna había permanecido integrada por semejante forma de institucionalidad económica. Pero esa quiebra, es importante enfatizarlo, ha de ser aprehendida e interpretada no en términos de simple explotación económica, toda vez que si dicho fenómeno de desintegración cultural puede incluir la explotación como una de sus particulares expresiones, la desborda como algo más amplio y complejo ${ }^{2}$.

La racionalidad típica y específica de los procesos de modernización capitalista, como es bien sabido, apareció como un tema ineludible para otro de los grandes clásicos de la sociología. Es importante notar que ese "espíritu capitalista" desmenuzado por Max Weber hubo de emerger a la contra de otro espíritu, el

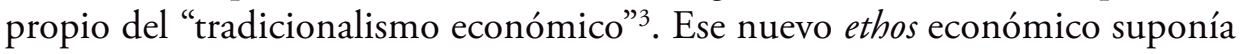
una ruptura radical con las formas tradicionales de comprender la satisfacción de las necesidades y también una metamorfosis radical en la organización temporal y material del trabajo. Werner Sombart, en ese sentido, señaló el crecimiento exponencial que hubo de experimentar la vida económica tras el advenimiento de lo que él denominara "espíritu burgués". En ese momento histórico la organización económica de ciertas sociedades europeas empieza a manifestar en su dinámica interna una transformación cualitativa de enormes proporciones pero, antes que nada, experimenta un impresionante incremento de su pura y simple extensión, amplificando notablemente su radio de acción, desbordando viejos límites culturales, ocupando nuevas y amplias zonas de la vida doméstica y social Sombart (1972: 186).

Porque el productivismo, y es ésta una tesis primordial, es una rareza etnográfica. Los instrumentos técnicos y la organización del trabajo no siempre fueron desarrollados hasta su límite máximo objetivo; muy al contrario, múltiples organizaciones sociales primitivas se reproducían por debajo de ese límite y no disponían de ninguna razón institucional ni albergaban ninguna compulsión

\footnotetext{
${ }^{1}$ Polanyi (1994a): 81.

${ }^{2}$ Polo Blanco (2015).

3 Weber (2003).
} 
psicosocial que las determinara a seguir produciendo de una manera expansiva, una vez alcanzado cierto límite ${ }^{4}$. Fue una verdadera revolución que tensó la capacidad humana de trabajar hasta llegar a los límites últimos de su capacidad; y es ahí donde podemos localizar el fenómeno de la explotación.

Pero debe comprenderse que esa hybris también produce y conforma un determinado ideal de vida que promueve una comprensión y una valoración económico-utilitaria de todos los aspectos de la existencia íntima, familiar y social. Porque el capitalismo no es únicamente un modo de producción o una estructuración determinada de las relaciones de propiedad; es algo mucho más complejo. El capital coloniza la subjetividad, la produce. Y, en ese sentido, puede sostenerse que el capitalismo también produce (y a través de ello se reproduce él mismo de forma persistente) violencia semiótica, esto es, un terrorismo del signo mercantil por medio del cual toda realidad humana va quedando re-codificada y re-significada a la escala de una mercantilización cada vez más omnímoda. Los esquemas intelectuales y los marcos axiológicos, en este contexto, empiezan a quedar adheridos a un régimen de significación que los redefine a través de una semántica totalizadora generada en los parámetros de lo puramente económicomercantil.

R. H. Tawney, en su descripción de esa "sociedad adquisitiva" que se acaba decantando con el despliegue del industrialismo moderno, identifica el nomos de dicha sociedad en la consecución de la riqueza de una manera siempre creciente e ilimitada; ilimitada en el sentido de que dicho objetivo se persigue por él mismo, sin que dicha producción de riqueza esté vinculada a algún otro objetivo comunitario o norma social (1972: 36). La actividad económica, al quedar emancipada de cualquier otra institución o normal social, no encuentra su sentido sino dentro de sí misma; se torna, en efecto, autorreferencial. Esa actividad económica, así vivida y conceptualizada, es incapaz de trascenderse a sí misma para buscar un significado social que la dote de límites y dirección, y la mecánica de las fuerzas del mercado se autoorganiza en una dinámica efectivamente solipsista y, por ello mismo, carente de cualquier normatividad ético-social que esté más allá de su propia actividad inmanente. Y a través de estas transformaciones es como la vida humana, en muchas de sus facetas, fue decantándose como fuerza meramente económica (Spranger, 1988: 186).

${ }^{4}$ Sahlins (1977): 55. 
El homo oeconomicus constituía una hipérbole analítica cuyo correlato histórico, empero, suponía un aparato institucional que de facto insertaba a los individuos en el orden social a modo de meros "sujetos económicos" 5 . Desde esa perspectiva, el tan manido "Hombre económico" había de comprenderse como la figura esencial de esa disciplina cada vez más notoria y determinante dentro del universo de las ciencias sociales; el denominado "imperialismo de lo económico" expresaba ese proceso por medio del cual la ciencia económica ortodoxa acabó erigiéndose en paradigma hegemónico, esto es, en esa ciencia matriz capaz de exportar su metodología y sus presupuestos teóricos al resto de las ciencias sociales, convirtiéndose con ello es una especie de "ciencia sagrada" con capacidad analítica omnicomprensiva. Pero no debemos olvidar, y debemos hacer hincapié en ello, que esta expresión teorético-ideal del homo oeconomicus se produjo acompasadamente a un proceso histórico efectivo por medio del cual toda la vida social de las comunidades humanas iba quedando progresivamente sumida en una creciente totalización tecno-económica. Y es ahí donde va cobrando realidad y vigor una imagen cada vez más económica del mundo.

En un lapso de tiempo relativamente breve se produce un trastrocamiento radical y revolucionario de todos los cimientos sociales y, en ese sentido, lo que Polanyi denominara "ficción mercantil" acabó cobrando patente efectividad en la historia de las sociedades humanas sometidas al avance del sistema de mercado ${ }^{6}$. $\mathrm{O}$, siendo más precisos con el lenguaje, más que acabar de efectuarse habríamos de decir que empezó a hacerlo, toda vez que tal proceso de mercantilización se desplegó hasta el límite mismo en el que una sociedad puede aguantar dicho desarrollo. Y, precisamente por ello, el proceso no llegó a culminar. En este punto, resulta muy pertinente traer a colación la noción polanyiana de "doble movimiento", que es de una importancia capital a la hora de aprehender la textura de su interpretación de los procesos históricos constitutivos de las modernas sociedades industriales. "La sociedad se protegía contra los peligros inherentes a un sistema de mercado autorregulado" 7 . En el preciso momento en el que el mecanismo del mercado autorregulado empezaba a extender su dominio y su radio de acción hasta el nervio mismo de la comunidad humana, esto es, hasta el ámbito del proceso del trabajo, en ese preciso momento, decimos, la sociedad tuvo que inventar dispositivos y configurar instituciones que restringían ese avance irrestricto de la dinámica mercantilizadora (Dale, 2010; Thompson, 1995).

\footnotetext{
${ }^{5}$ Dalton (1974): 42.

${ }^{6}$ Polanyi (1994a): 82.

${ }^{7}$ Polanyi (2003): 127.
} 
Polanyi siempre combatió la que él consideraba la más funesta de las falacias, a saber, esa ilegítima identificación entre economía humana en general y (sistema de) mercado ${ }^{8}$. Las sociedades humanas historiográfica y etnográficamente documentadas jamás habían funcionado a través de unos patrones semejantes. Por ello, la implantación de un mercado de mano de obra enteramente libre (esto es, liberado de toda regulación institucional) suponía una profunda dislocación social, un quebranto de la norma antropológica que había regido en prácticamente todas las sociedades históricas estudiadas y conocidas ${ }^{9}$. Es entonces, con la llegada de la "civilización decimonónica", cuando empieza a cobrar sentido la expresión sociedad de mercado, un sintagma que denota un tipo de orden social absolutamente novedoso en la historia de las civilizaciones humanas, esto es, una sociedad donde el aparato tecno-económico empieza a fagocitar todos los otros tejidos sociales de suyo no-económicos de los que previamente se había emancipado y desgajado para, como decimos, reabsorberlos en la legalidad de su dinámica interna.

Se trató, en suma, de un violento proceso de expansiva mercantilización que afectó, en el límite, al conjunto de la sociedad. El código económico se fue instalando de forma imperialista y avasalladora en lo político, en lo moral, en lo intelectual, en lo estético; empezó a ser la principal clave que abría y posibilitaba todos los espacios de comprensión de las realidades humanas. Así lo expresaría algún tiempo después Louis Dumont, influido directamente por la obra de Karl Polanyi, cuando señalaba que una insólita consistencia emergía y una nueva dimensión de la realidad coagulaba con unos contornos marcadamente diferenciados, delimitados, desgajados de su vieja mezcolanza con otros nervios de lo social. Un complejo proceso que desembocó, finalmente, en la emancipación del punto de vista económico como algo separado, como algo que podía encerrarse en las fronteras epistémicas de una disciplina escindida, autónoma y que, evidentemente, se codificaba completamente al margen de las valorizaciones y las categorías que se desprenden de lo político y de lo moral (Dumont, 1999: 45).

La perspectiva económica acabó ensamblándose en una unidad coherente y omnicomprensiva, y terminó por generar una cultura vertebrada en todos sus marcos de percepción y acción por una axiología economicista y una filosofía esencialmente utilitarista ${ }^{10}$. Es importante comprender, en ese preciso sentido,

\footnotetext{
${ }^{8}$ Polanyi (1994a): 77.

${ }^{9}$ Polanyi (1994a): 81.

${ }^{10}$ Polanyi (1994a): 82.
} 
que la sociedad de mercado fue generando un estilo de vida, una imagen del mundo y una autocomprensión del ser del hombre. Generó, en suma, una "mentalidad de mercado" 11 . Porque, según nos quiere indicar Polanyi, no tenemos delante un mero sistema económico; no se trata, en efecto, solamente de un determinado modo de producción. Por el contrario, se trata de toda una visión del mundo que penetra casi todas las fibras morales e intelectuales de la trama vital humana. Y, hemos de señalarlo, también las clases populares y trabajadoras acabaron sucumbiendo (incluso en sus justas reivindicaciones) a dicha lógica economicista ${ }^{12}$.

Georg Simmel, en un trabajo cuya envergadura y profundidad son sencillamente inigualables, nos sitúa certeramente en el meollo de lo que aquí queremos dibujar a tenor de la obra polanyiana. El filósofo y sociólogo alemán, en efecto, establecía una correlación casi isomórfica entre el modo de inteligencia puramente calculador, la extensión generaliza del uso del dinero, la visión racionalista y mecanicista del universo, la concepción abstracta del tiempo, la previsibilidad mensurable de las formas de vida modernas y fenómenos tan aparentemente triviales como la generalización del uso del reloj de bolsillo. Todos estos elementos se funden e interrelacionan en un mismo magma; unos y otros se corresponden entre sí, se coimplican, se retroalimentan y configuran una visión del mundo sistemática y coherente ${ }^{13}$.

La gran falacia económica denunciada por Polanyi, que era una tal falacia precisamente porque la infundada y fementida identificación de toda economía humana posible con los parámetros propios de la economía de mercado quedaba desmentida por milenios de cultura y civilización humana, dicha falacia, decíamos, acabó empero teniendo un paradójico cumplimiento, toda vez que con el desarrollo de las modernas sociedades industriales comenzó a tornarse efectiva la traumática y revolucionaria identidad entre sistema de mercado y sociedad. Dicha identidad empezó a ensamblarse precisamente en tanto en cuanto todas las instituciones sociales en principio ajenas a lo económico fueron quedando organizadas histórico-institucionalmente por un sistema de mercados libres y formadores de precios ${ }^{14}$. Y la crítica polanyiana a esa utopía liberal consistente en proyectar una sociedad reducida casi toda ella a mercado no se queda, pues,

\footnotetext{
${ }^{11}$ Polanyi (1994b).

${ }^{12}$ Lafargue (1998).

${ }^{13}$ Simmel (2003): 576-577.

${ }^{14}$ Polanyi (1994a): 84.
} 
en la mera denuncia de la explotación económica de una clase social a manos de otra; fenómeno, por otro lado, en absoluto infravalorado o ignorado por Polanyi. Pero sí se puede decir que la suya trata de ser una crítica cultural más amplia que denuncia la desasosegante expansión de lo mercantil y de lo utilitario a todo el conjunto de la vida social. La paradójica realización de la falacia económica, aunque no llegó a cumplirse hasta el límite último de sus posibilidades, significó una profunda metamorfosis histórica que rompía una norma milenaria que determinaba no entregar la totalidad de los resortes de la vida social a un mecanismo de libre compraventa mercantil. Cuando la falacia económica cobró efectividad histórica, en suma, cumplió un violento resquebrajamiento antropológico que bien cerca estuvo de descomponer los lazos comunitarios hasta un punto de no retorno.

Al hilo de lo anterior, habríamos de señalar que en una utopía liberal enteramente cumplida, esto es, en el marco de la hipotética realización de una sociedad reducida toda ella a los parámetros del sistema de mercado, si tal cosa llegase a suceder, desaparecería todo tipo de valoración que no fuera la estrictamente emanada del funcionamiento automático del mercado formador de precios. La trayectoria tendencial de dicha configuración social, utópica de raíz, como señala Polanyi, se dirigiría a la máxima economización formal de todos los contenidos antropológicos De lo que se está hablando, en suma, es de la identificación de toda praxis humana con una racionalidad que funciona únicamente a base de maximizar la propia utilidad en un entorno de mercado perfecto y que, en definitiva, aparece enteramente despojada de cualquier revestimiento no-económico. Las "teorías de la elección racional", que tan buena prensa adquirirían a lo largo del siglo XX, llegarían a ser meridianamente explícitas al respecto, contemplando tal modelo como el más adecuado para comprender la acción humana ${ }^{15}$.

Es verdad que los seres humanos reales jamás se comportaron como prescriben los modelos teóricos de la doctrina económica ortodoxa ${ }^{16}$. Y es por ello que Polanyi se enfrenta a ese "racionalismo económico" que concibe la vida social como un conglomerado de átomos maximizadores de utilidad que viven y funcionan guiados únicamente por una racionalidad formal-economizadora y utilitaria, más allá de la cual nada ya tendría sentido. Debemos, no obstante, consignar la apreciación de Harold J. Laski: "Y no es que la idea de la riqueza por la riqueza sea una novedad de repente en una época determinada, no. Seguramente

\footnotetext{
${ }^{15}$ Gauthier (1994).
}

${ }^{16}$ Polo Blanco (2014). 
es tan vieja como la civilización misma [...] Pero sólo en estos ańos comienza a impregnar la mentalidad colectiva" ${ }^{17}$. Porque, en efecto, dentro de esta visión del mundo que ahora empezaba a cristalizar toda acción humana que no encaje con semejantes parámetros de racionalidad irá apareciendo cada vez más como irracional, disfuncional y carente de valor. $Y$ es por eso que el empleo del término alemán Weltanschauung no es casual ni gratuito, por lo que venimos diciendo hasta ahora, y el propio Polanyi la emplea ${ }^{18}$.

Cuando lo económico-formal empieza a erigirse en una totalidad sin alteridad, que es precisamente el proceso que estamos tratando de delimitar, todo aquello que no responde a los parámetros de semejante racionalidad economizadora empieza a desecarse, y ningún valor o norma externos a lo estrictamente económico (en un sentido formal-maximizador) puede guiar la praxis de los hombres; una praxis que, precisamente por estar prefigurada dentro del aparato institucional de un sistema de mercado autorregulado, empieza a quedar enteramente encauzada cada vez más sobre fundamentos normativos meramente mercantiles.

La filosofía social fundada sobre tales principios fue tan radical como fantástica. Hacer de la sociedad un conjunto de átomos y de cada individuo un átomo que se comporta según los principios del racionalismo económico, colocaría el total de la existencia humana, con toda su riqueza y profundidad, en el esquema referencial del mercado ${ }^{19}$.

En este texto, volvemos a insistir en ello, Polanyi dice que los efectos del mercado casi llegan a determinar por completo al conjunto de la sociedad, de la misma manera que advierte que la totalidad de la existencia humana ha estado cerca de ser colocada enteramente dentro del esquema del mercado; es esto muy importante, toda vez que la sociedad se defendió espontáneamente, de muy diversas formas, contra ese proyecto utópico consistente en una totalización económica de la existencia humana. Más allá, o más acá, de la explotación estrictamente económica, el mercado aparecería como constructor de personalidades, como forjador de caracteres. Anunciaba Erich Fromm, con timbre

\footnotetext{
${ }^{17}$ Laski (1953): 19.

${ }^{18}$ Polanyi (1994a): 85.

${ }^{19}$ Polanyi (1994a): 86.
} 
ominoso, que ya estaban dadas unas condiciones socioculturales dentro de las cuales había de producirse un violento adelgazamiento de la racionalidad humana, cuya expresión fue quedando reducida a un funcionamiento instrumental meramente optimizador y adaptativo. Los individuos ya se experimentaban a sí mismos (se autoconcebían) como mercancía ${ }^{20}$. Karl Polanyi podría muy bien leer en estos pasajes de Fromm un paroxismo de sus "mercancías ficticias", ya que no sólo tierra, trabajo y dinero habían ido mercantilizándose, sino que lo más íntimo de la subjetividad humana quedaba troquelado a la escala de lo enajenable y vendible. Michael Foucault se acercaría a estos desarrollos en uno de sus cursos en el Collège de France, en 1979:

Ahora bien, ¿qué función tiene esa generalización de la forma «empresa»? Por un lado se trata, desde luego, de multiplicar el modelo económico, el modelo de la oferta y la demanda, el modelo de la inversión, el costo y el beneficio, para hacer de él un modelo de las relaciones sociales, un modelo de la existencia misma, una forma de relación del individuo consigo mismo, con su entorno, el futuro, el grupo, la familia ${ }^{21}$.

Podemos concluir, en la línea de lo que venimos comentando, que el economicismo se presenta como un marco de comprensión adecuado a una sociedad que, en efecto, vive en el trance de ir siendo reducida cada vez más a la mera reproducción de su sistema económico; pero se produce a la vez el espejismo de pretender extender dicha comprensión economicista a toda sociedad humana posible y concebible cuando, en todo caso, dicho esquema es válido únicamente para la moderna sociedad industrial. "Por lo que respecta a la sociedad, la doctrina pareja fue que sus instituciones estaban "determinadas» por el sistema económico. El mecanismo de mercado creó para ello el espejismo del determinismo económico como si fuera una ley general para toda la sociedad humana" ${ }^{22}$. El espejismo del "determinismo económico", que contribuyó a forjar buena parte de los fundamentos de las ciencias sociales en general y, por supuesto, de las ciencias económicas en particular (Mingione, 1994; Polo Blanco, 2016), se instaló también en el imaginario colectivo y en la cultura popular, construyendo toda

\footnotetext{
${ }^{20}$ Fromm (1985): 82.

${ }^{21}$ Foucault (2009): 239.

22 Polanyi (1994a): 84.
} 
una psicología social. Pero además, dicho determinismo constituía un elemento de obstrucción imaginativa, en el sentido de contribuir decisivamente a la imposibilidad de concebir un orden social distinto; uno en el que la legalidad emancipada de lo económico no determine monstruosamente todos los aspectos de nuestra vida. Por ello Karl Polanyi combatió sin descanso contra el funesto halo del determinismo economicista ${ }^{23}$.

Todo este proceso, por medio del cual el subsistema económico impone irrestrictamente su legalidad a todo el orden social, precisamente porque dicho subsistema se había emancipado del resto del tejido social, como advertía Polan$\mathrm{yi}^{24}$, comportaba a sus ojos una tremenda revolución y desbaratamiento de los cimientos de la comunidad humana, pues ahora la sustancia misma del hombre era depositada en la dinámica de un mecanismo ciego dentro del cual se determinaba su valor y su precio y, con ello, su derecho o no a sobrevivir; y no sólo se determinaba su derecho o no a pervivir, sino que configuraba un determinado modo de existencia culturalmente desarraigado y despojado. El ser social del hombre era colonizado violentamente, en todas sus facetas, por la legalidad inherente al sistema de mercado. Las palabras de Polanyi son, en este aspecto, poderosas y dramáticas ${ }^{25}$.

Este nuevo mecanismo institucional destejía viejas normatividades para configurar un nuevo espacio de los lazos humanos. Por primera vez en la historia, en efecto, el sustento de todo hombre dependía en última instancia de su habilidad para poder vender su abstracta capacidad de trabajar en un mercado laboral que tal vez se hallara vacío de demanda; y eso suponía, en suma, que la participación en la vida material y simbólica de la sociedad (en la producción de bienes y en la distribución y disfrute de los mismos) dependía de un mecanismo incontrolable de precios fluctuantes; pues, como venimos anunciando, la propia fuerza de trabajo era tratada como una mercancía y, al ser así, tenía que buscar su salida en el mercado. Pero bien pudiera suceder que, sujeta a las fluctuaciones de la oferta y la demanda, esa fuerza de trabajo llegase a valer nada. Y ese "valer nada" en el mercado laboral conlleva la ruina y la inanición.

Mercantilizar toda la sustancia humana supone un atentado antropológico cuyas consecuencias desintegradoras son de largo alcance. Pero partiendo de esa

\footnotetext{
${ }^{23}$ Polanyi (1991).

${ }^{24}$ Polanyi (2003): 121.

25 Polanyi (1994a): 83.
} 
misma perspectiva, no debe ignorarse que la devastación cultural y antropológica afecta también al hábitat natural de las gentes comunes, toda vez que la tierra es primordialmente atacada por los procesos imparables de mercantilización. Y en ese sentido, Polanyi anticipa en sus reflexiones algunos elementos decisivos del ulterior pensamiento crítico de corte ecologista.

La tierra es parte de la naturaleza y está tan poco pensada para la venta como el hombre. Las ficciones legales y económicas bajo las que la tierra puede ser puesta bajo el control del mercado del suelo son, en general, análogas a las que encontramos en el caso del trabajo. En realidad, la tierra es el hábitat del hombre, el emplazamiento de sus actividades, la fuente de su vida, el lugar de su seguridad, de las estaciones y la tumba. Ni siquiera los suelos pueden soportar el tratamiento comercial. Erosionados, arrasados, pulverizados, todas las regiones corren el riesgo de la regresión al bosque primario, el pantano o el desierto. El derroche de recursos daña nuestro futuro [...] Tan cercana es la vida del hombre a la de la naturaleza, que a menos que el destino económico del producto del suelo sea organizado de manera tal que permita llevar una vida normal a aquellos que trabajan la tierra, la agricultura será destruida ${ }^{26}$.

La deshumanización de una agricultura organizada toda ella en base al beneficio capitalista produce despilfarro y agotamiento excesivo de los recursos, además de una mercantilización de las formas de vida de los trabajadores del campo. Polanyi, por lo tanto, estaba apuntando ya a los nefastos efectos de una mercantilización irrestricta de la tierra y de todos los recursos naturales que de ella proceden, y entiende que, para evitar la devastación mercantil del hábitat natural, la organización de dichos recursos habrá de fundamentarse en una institucionalidad ajena al sistema de mercado ${ }^{27}$.

\footnotetext{
${ }^{26}$ Polanyi (2014): 125.
}

27 Zuberman (2013). 


\section{Aristóteles entrevió un peligro incipiente}

Ejecutemos ahora un olímpico y retrospectivo salto en el tiempo, y acudamos al siglo IV a. C. Allí encontraremos a Aristóteles escribiendo, en cierto modo, desde una posición de reacción ante los procesos de creciente comercialización y mayor especialización del trabajo que empiezan a tener lugar en la Atenas de su época, y late en sus palabras un cierto temor a que dichos procesos acaben produciendo una deriva disolvente en la comunidad de ciudadanos (koinonia ton politon). Ése es, precisamente, el motivo último que se detecta en el fondo de su "filosofía económica" 28 .

Hemos de comprender, en primer lugar, que para Aristóteles sí existe una forma legítima de intercambio. Por lo tanto, no era contrario a toda forma de comercio.

Así pues, una especie de arte adquisitivo es naturalmente una parte de la economía: es lo que debe facilitar o bien procurar que exista el almacenamiento de aquellas cosas necesarias para la vida y útiles para la comunidad de una ciudad o de una casa. Y parece que la verdadera riqueza proviene de éstos, pues la provisión de esta clase de bienes para vivir no es ilimitada, como dice Solón en un verso [...] Y la riqueza es la suma de instrumentos al servicio de una casa y de una ciudad. Por tanto, es evidente que hay un arte de adquisición natural para los que administran la casa y la ciudad ${ }^{29}$.

El juego de las distinciones empieza a ponerse en marcha en tanto en cuanto aparece una forma "legítima y natural" de adquirir riqueza; lo cual, evidentemente, nos ha de remitir a una forma de adquirirla enteramente ilegítima y, de hecho, peligrosa. Aristóteles nos está hablando de un peligro latente de corrosión y descomposición en el seno de la comunidad civil. Porque el telos de la medicina, por ejemplo, es curar y hacer recobrar la salud, no producir ganancia; y aquello que, por el contrario, empieza a ejecutarse no ya para cumplir su finalidad

\footnotetext{
${ }^{28}$ Polanyi (1976a).

${ }^{29}$ Aristóteles (2000): 1256b13.
} 
natural, sino a producirse para la venta, está siendo prostituido y desviado de su norma inherente ${ }^{30}$.

Aristóteles, por lo tanto, advierte que existe otra forma de producir y adquirir riqueza, que no tiene ya nada que ver con un arte adquisitivo natural:

Existe otra clase de arte adquisitivo, que precisamente llaman -y está justificado que así lo hagan-crematística, para el cual parece que no existe límite alguno de riqueza y propiedad. Muchos consideran que existe uno solo, y es el mismo que el ya mencionado a causa de su afinidad con él. Sin embargo, no es idéntico al dicho ni está lejos de él. Uno es por naturaleza y el otro no, sino que resulta más bien de una cierta experiencia y técnica ${ }^{31}$.

En ese sentido, procede a distinguir entre el uso propio de los objetos, que es un uso natural, y aquel otro uso (el crematístico) que no lo es:

Ambos usos son del mismo objeto, pero no de la misma manera; uno es el propio del objeto, y el otro no. Por ejemplo, el uso de un zapato: como calzado y como objeto de cambio. Y ambos son utilizaciones del zapato. De hecho, el que cambia un zapato al que lo necesita por dinero o por alimento utiliza el zapato en cuanto zapato, pero no según su propio uso, pues no se ha hecho para el cambio. Del mismo modo ocurre también con las demás posesiones, pues el cambio puede aplicarse a todas, teniendo su origen, en un principio, en un hecho natural: en que los hombres tienen unos más y otros menos de lo necesario. De ahí que es evidente también que el comercio de compra y venta no forma parte de la crematística por naturaleza, pues entonces sería necesario que el cambio se hiciera para satisfacer lo suficiente ${ }^{32}$.

Lo que se pregunta el filósofo griego es si eso que él denomina más propiamente chrematistiké (todo aquello que tendría que ver, por así decir, con el valor

\footnotetext{
${ }^{30}$ Basañez (1994): 141.

${ }^{31}$ Aristóteles (2000): 1257a.

${ }^{32}$ Aristóteles (2000): 1257a2.
} 
de cambio) puede considerarse como una parte de la oikonomía (que tendría que ver con el valor de uso de las cosas), o bien es algo de distinta especie. Es ésta una cuestión crucial y determinante.

Para Aristóteles, como señalábamos hace un momento, el intercambio puede ser considerado como algo benévolo y conforme a naturaleza siempre y cuando esté destinado a cumplir las necesidades de autosuficiencia y reproducción de la casa, del ámbito doméstico. Es decir, que no todo intercambio habrá de degenerar necesariamente en una forma mórbida o ilegítima. Un intercambio entre equivalentes útiles, cuando las comunidades humanas son ya de mayor población y no todas tienen de todo, no debe dar lugar a un tipo desmedido e ilegítimo de crematística. Pero cuando se sobrepasan los límites de la autosuficiencia y la autarquía, esto es, cuando se intercambia no ya con vistas a mantener dicha autosuficiencia de la casa (y de la polis) sino con el fin de incrementar sin límite la riqueza, nos adentramos en otra forma radicalmente distinta de intercambio. $Y$ es sólo entonces cuando surge esa otra forma de intercambio ilegítimo y antinatural, a saber, aquél en el que todo el movimiento de bienes se hace sólo y exclusivamente para la obtención de un beneficio extra, esto es, para la obtención de un excedente de valor que no estaba presente al comienzo de dicho movimiento de intercambio ${ }^{33}$.

Aunque en ocasiones pudiéramos hallar en el texto cierta ambigüedad semántica en torno a la noción de crematística, sin embargo, en diversos pasajes aristotélicos es la actividad comercial con afán de ganancia la que se subsume más estrictamente bajo ese nombre mientras que, por el contrario, la economía doméstica es nombrada más frecuentemente con otras fórmulas, como por ejemplo "riqueza según la naturaleza". Y en ese sentido, si hay algo extremadamente alejado del intercambio natural es el préstamo a interés. El dinero engendrando dinero es, concluye Aristóteles, el más antinatural y aberrante de todos los negocios concebibles:

Ahora bien, este arte, como hemos dicho tiene dos formas: una, la del comercio de compra y venta, y otra, la de la administración doméstica. Esta es necesaria y alabada; la otra, la del cambio, justamente censurada (pues no es conforme a la naturaleza, sino a expensas de otros). Y muy razonablemente

\footnotetext{
${ }^{33}$ Aristóteles (2000): 1257b11.
} 
es aborrecida la usura, porque, en ella, la ganancia procede del mismo dinero, y no de aquello para lo que éste se inventó [...] pues lo engendrado es de la misma naturaleza que sus generadores, y el interés es dinero de dinero; de modo que de todos los negocios éste es el más antinatural ${ }^{34}$.

El intercambio comercial, por lo tanto, debiera permanecer siempre subordinado al mantenimiento y recurrencia de esa comunidad política; y por eso mismo, una actividad comercial que escapara de esos límites y se dedicara a la pura ganancia, al intercambio ilimitado que sólo persigue maximizar el beneficio una y otra vez, podría suponer una corrosión de los lazos comunitarios propios de la economía doméstica ${ }^{35}$. Como observamos en Ética a Nicómaco, Aristóteles intenta hallar la forma de que todo intercambio sea justo y proporcionado, esto es, que pueda resultar mutuamente beneficioso o que al menos ninguno de los intervinientes resulte flagrantemente perjudicado (1164a22). Las relaciones comerciales, en ese sentido, también deben ser amistosas, con toda la carga semántica que dicho adjetivo arrastra dentro del léxico filosófico aristotélico (Aristóteles, 1159b/1160a28-30). Es por todo ello que algunas reflexiones contemporáneas sobre las relaciones entre ética y economía acuden al aristotelismo (Nussbaum, 1992; Conill Sancho, 2013).

La vida honorable, o "vida buena", no podía consistir en la acumulación indefinida de bienes y, si en todo caso, tal modo de vida llegara a generalizarse, no sería sino a costa de una degeneración antinatural de la vida social y política que, en última instancia, sería el fruto nocivo de una desmesura contraria al buen sentido de la vida pública. Ésa era la hybris, el gran exceso de la compraventa encaminada exclusivamente al lucro; el exceso antinatural de los que dedican todo su tiempo y su quehacer al negocio y a la obtención del beneficio, supeditando a esa tarea todas las facultades intelectivas y morales, las cuales pierden por ello su nobleza política y su virtud cívica ${ }^{36}$. Ese comportamiento, ese modo de vida, fulgía ante los ojos de Aristóteles como esencialmente antipolítico, en un sentido muy radical.

El fin de la economía doméstica aristotélica, que Karl Polanyi identificaría con la economía en sentido substantivo, no era la acumulación ilimitada de

\footnotetext{
${ }^{34}$ Aristóteles (2000): 1258b4.

${ }^{35}$ Borisonik (2013).

${ }^{36}$ Aristóteles (2000): 1257b15.
} 
riqueza, sino el mantenimiento y el sustento de la comunidad. Esa economía genuina, por así decir, se refería a todas aquellas actividades que garantizaban el sostenimiento cotidiano de la familia y la reproducción material de la ciudad. La ruptura de ese sutil equilibrio por parte de una crematística avasalladora (que Aristóteles sólo dibujaba como una ominosa hipótesis posible y probable) es lo que, en cambio, quedaría modernamente ejecutado con las exigencias de una racionalidad económica formal institucionalizada bajo un prisma de competitividad comercial generalizada y con la entronización normativa de la maximización de ganancias. La eudemonía aristotélica, término que puede ser traducido como felicidad o plenitud virtuosa (Adomeit, 1995), es enteramente incompatible con una forma de vida supeditada a la inmanencia de lo productivo, a la lógica de la ganancia y a las exigencias del negocio lucrativo.

\section{El Sumak Kawsay}

La noción Buen vivir ha aparecido recientemente en el vocabulario de algunos países de América Latina que han experimentado importantes procesos de transformación social y política en la primera década del siglo XXI. Dicha noción cobró un relevancia notabilísima a través del reconocimiento obtenido en las Asambleas constituyentes de Ecuador (sumak kawsay, en quichua) y Bolivia (suma qamaña, en aymara), aprobadas entre 2008 y $2009^{37}$. Estas nociones hacen referencia a ciertos elementos sociales y axiológicos anclados en los modos de vida armónicos que existieron y todavía subsisten en las relaciones comunitarias de los pueblos indígenas, cuyas cosmovisiones y valores tienen raíces milenarias, y que terminan por cristalizar como un pensamiento alternativo al desarrollismo capitalista occidental y como propuesta política que acaba integrándose como elemento crucial en discursos transformadores y emancipadores ${ }^{38}$.

Como bien señala Catherine Walsh, los nuevos textos constitucionales, muy inspirados en esas cosmovisiones andinas (y también afrodescendientes), preten-

dieron constituir una ruptura económica, cultural e incluso espiritual con los modelos propios de la Modernidad colonialista, desarrollista y neoliberal.

\footnotetext{
${ }^{37}$ Belotti (2014).

${ }^{38}$ Vega (2014).
} 
De esta manera, la incorporación del sumak kawsay o buen vivir representa un hito trascendental [...] Al proponer una filosofía de bienestar radicalmente opuesta al bienestar neoliberal, este último con su centro en el individuo y en un individualismo alienante de posesión -el "tener", que se mencionó anteriormente-, y caracterizado por la falta de articulación social, la nueva Constitución Política asume la responsabilidad y necesidad de terminar con el modelo neoliberal, pero también de comprometerse con la tarea histórica de re-fundar el Estado y la sociedad de manera jamás considerada en casi doscientos años de vida republicana ${ }^{39}$.

Partiendo de un sustrato cultural preexistente, la intelectualidad del mundo indígena boliviano y ecuatoriano, como era de esperar, cumplió un papel determinante en la reelaboración, traducción y codificación de la noción de Buen vivir, en su consolidación epistemológica y en su potente proyección dentro del discurso político alternativo y contrahegemónico ${ }^{40}$.

Es verdad que la noción de buen vivir no es unívoca, sino polisémica. El concepto alberga dentro de sí una vertiente más indigenista o cultural-ancestral, una dimensión explícitamente ecologista y post-desarrollista, otra económica y por último un aspecto de intensificación democratizadora y ciudadana. Todas estas dimensiones se vinculan entre sí, pero en ocasiones surgen fricciones y contradicciones internas. En cualquier caso, desde todas ellas se impugnan los modelos de desarrollo hegemónicos en las últimas décadas del siglo XX, a saber, la gobernanza neoliberal y el paradigma desarrollista-extractivista. Y si hay una crisis del capitalismo, o un cuestionamiento del mismo, será en base a la problemática decisiva del medio ambiente y de la destrucción depredadora de los ecosistemas. Porque una simple "reforma verde" del capitalismo, sin entrar a discutir su concepto esencialmente mercantilizador de los recursos naturales, tampoco tiene demasiado recorrido ${ }^{41}$.

Sin perder de vista que "el buen vivir no se limita a las condiciones económicas, políticas, socioculturales y ambientales sino que también involucra y pone en consideración condiciones epistémicas", puesto que "pretende poner en práctica y asumir con seriedad filosofías de vida que rompen radicalmente con el marco

${ }^{39}$ Walsh (2009): 228.

${ }^{40}$ Hidalgo, Arias y Ávila (2014); Cubillo e Hidalgo (2015).

${ }^{41}$ Gudynas (2010). 
filosófico-político que orienta el Estado y la sociedad neoliberal” ${ }^{42}$. Reestablecer y reconstruir la comunión entre la naturaleza y las personas sería, en ese sentido, un acto liberador y descolonizador. ¿¿Por qué? Porque quebrantaría una específica lógica del poder y también una epistemología dominante, basadas ambas en el dominio explotador de la naturaleza (y de los otros hombres). La propia mitología semítica y griega que late en la médula de la civilización occidental abre esa perspectiva de dominio absoluto sobre la naturaleza ${ }^{43}$. Por todo ello, esa escisión sólo podrá volver a conciliarse a través de un quebranto descolonizador que abandone los esquemas económicos y culturales de la cosmovisión occidental. Es por eso que estos textos constitucionales tienen un alcance refundador y descolonizadores, esto es, propician o posibilitan una salto más allá de (y por fuera de) la modernidad colonial.

Mónica Chuji, intelectual ecuatoriana perteneciente a la nacionalidad kichwa, señalaba que primero la ideología del progreso (que colapsa en los campos de concentración) y después la ideología del desarrollo (tras la segunda guerra mundial), fundamentaron una visión del mundo bestialmente productivista y economicista:

Quiero advertir dos dimensiones de la perversidad del discurso del desarrollo. La primera hace referencia a la relación del hombre con la naturaleza, que en el discurso del desarrollo es puramente instrumental y que ahora amenaza con convertirse en un problema de sobrevivencia de la especie humana. La segunda dimensión hace referencia a la subordinación de la ética al crecimiento económico; si para crecer en términos económicos es necesario borrar de la superficie del planeta hasta el último árbol, la noción de desarrollo no tiene impedimentos ${ }^{44}$.

La noción de "buen vivir" quedaría incardinada en un contrapunto epistemológico y cultural (quizás podríamos decir, incluso, espiritual) a esa cosmovisión desarrollista y economicista puesta en juego por la racionalidad moderna occidental.

\footnotetext{
${ }^{42}$ Walsh (2009): 230.

${ }^{43}$ Medina (2001): 19.

${ }^{44}$ Chuji (2014): 157.
} 
Alberto Acosta indicaba que, más allá del articulado constitucional, el Buen vivir (que no debe confundirse con el "bienestar occidental") debe ser entendido como la construcción colectiva de una nueva forma de vida. Por lo tanto, los cambios jurídicos y estatales deben ir acompañados de una transformación cultural.

En la cosmovisión indígena no hay el concepto de desarrollo entendido como la concepción de un proceso lineal que establezca un estado anterior o posterior. No hay aquella visión de un estado de subdesarrollo a ser superado. Y tampoco un estado de desarrollo a ser alcanzado forzando la destrucción de las relaciones sociales y la armonía con la Naturaleza (Acosta, 2010: 11).

Asumiendo los postulados del Sumak Kawsay se avanza hacia la impugnación de los modelos de desarrollo importados desde las potencias occidentales altamente industrializadas. La racionalidad occidental heredada, además, siempre vivió instalada en una radical escisión hombre-naturaleza, por la cual ésta última era un objeto externo al que dominar y explotar (esta concepción quedó bien asentada y cristalizada en la filosofía de Francis Bacon, en el siglo XVII). De la naturaleza así entendida había de extraerse el máximo rendimiento posible.

Para empezar a enfrentar este añejo mensaje, sostenido en un divorcio profundo de la economía y la Naturaleza, hay que rescatar las verdaderas dimensiones de la sustentabilidad. Esta exige una nueva ética para organizar la vida misma. Se precisa reconocer los límites biofísicos de las actividades desarrolladas por los humanos. La realidad nos demuestra hasta la saciedad que la Naturaleza tiene límites. Y esos límites, aceleradamente alcanzados por los estilos de vida antropocéntricos, particularmente exacerbados por las demandas de acumulación del capital, son cada vez más notables e insostenibles (Acosta, 2010: 18).

Pueden existir mercados, siempre regulados y supeditados a una finalidad social que a su vez no menoscabe el entorno natural, pero no una sociedad de mercado en la cual la totalidad de las relaciones sociales y vitales queden mediadas por la mercantilización. El mercado puede ser un buen sirviente, pero un pésimo 
amo. Porque el Buen vivir, en suma, quiere buscar una economía más solidaria y no tan presidida por las pautas normativas de la pura competitividad ${ }^{45}$.

Algunos autores han señalado, no sin cierto, que la noción de Buen vivir es un neologismo construido ad hoc por la intelectualidad indígena, hasta el punto de que resulta difícil encontrar referencias a la misma en la prolija literatura etnográfica sobre comunidades andinas anterior al cambio de milenio ${ }^{46}$. Encontramos también que buena parte de dicha literatura alberga muchas carencias en lo referente a una contextualización adecuada y fundamentada en información empírica rigurosa. Por el contrario, las comunidades indígenas y campesinas andinas aparecen idealizadas y mixtificadas en una suerte de fabulación ahistórica que las presenta como una suerte de entidades puras (supervivencias precolombinas inmaculadas) basadas enteramente en principios sociales de reciprocidad y, por lo tanto, esencialmente "anti-mercado" y "anti-desarrollo" (una retórica que, en verdad, no deja de recordar al mito del "buen salvaje", que popularizó el filósofo Rousseau). Semejante perspectiva la podemos encontrar en Javier Medina, el cual sostiene que las comunidades amerindias son sociedades básicamente anti-mercantiles que habrían resistido durante quinientos años, en una suerte de inmaculado reducto geográfico e histórico, los embates de la aculturación desarrollista occidental ${ }^{47}$.

Pero, en cualquier caso, estas nociones han operado pragmáticamente a la hora de tejer un discurso y una práctica política, más allá de su eventual preexistencia histórica y etnográfica. El concepto ha sido determinante a la hora construir una identidad política nueva y a la hora de forjar un nuevo sujeto colectivo y, por lo tanto, también ha funcionando en buena medida como uno de esos "significantes vacíos" de los que hablaba Ernesto Laclau ${ }^{48}$. Y, en ese sentido, la elaboración intelectual e ideológica del concepto ha perseguido la estipulación y afianzamiento de un nuevo cuerpo de derechos fundamentales plasmados en los nuevos textos constitucionales que, a su vez, informan y orientan en buena medida (aunque no sin contradicciones) las políticas públicas ${ }^{49}$.

\footnotetext{
45 Acosta (2010): 23.

${ }^{46}$ Viola Recasens (2014): 63.

${ }^{47}$ Medina (2001): 176.

${ }^{48}$ Laclau (2013).

${ }^{49}$ Manosalvas (2014).
} 
El diagnóstico de una crisis civilizatoria, que emerge con fuerza en las diversas teorizaciones del Buen vivir, aparece tematizado con mucha penetración en la obra del economista y ambientalista mexicano Enrique Leff:

La problemática ambiental emerge como una crisis de civilización: de la cultura occidental; de la racionalidad de la modernidad; de la economía del mundo globalizado. No es una catástrofe ecológica ni un simple desequilibrio de la economía. Es el desquiciamiento del mundo al que conduce la cosificación del ser y la sobreexplotación de la naturaleza; es la pérdida del sentido de la existencia que genera el pensamiento racional en su negación de la otredad ${ }^{50}$.

El problema ambiental, que deviene ya crisis civilizatoria, hunde sus raíces en el tipo de racionalidad que pone en juego la cultura occidental. La "muerte entrópica del planeta" es el resultado de un determinado modo de ser y de estar en el mundo que, a la postre, ha resultado ser suicida. Pues, como bien ha resaltado el ecuatoriano Fander Falconí, estamos ante una auténtica crisis civilizatoria que evidencia la inviabilidad de los modelos vigentes de producción y consumo ${ }^{51}$.

Concluía Leff que "el conocimiento se ha vuelto contra el mundo, lo ha intervenido y dislocado" (2004: IX). Y, en la estela de la Escuela de Frankfurt, comprende que el problema hunde sus raíces en la cosificación del mundo y de la naturaleza ejercida por esa racionalidad avasalladora.

La crisis ambiental irrumpe en el momento en el que la racionalidad de la modernidad se traduce en una razón anti-natura. No es una crisis funcional u operativa de la racionalidad económica imperante, sino de sus fundamentos y de las formas de conocimiento del mundo. La racionalidad ambiental emerge así del cuestionamiento de la sobreeconomización del mundo, del desbordamiento de la racionalidad cosificadora de la modernidad, de los excesos del pensamiento objetivo y utilitarista ${ }^{52}$.

\footnotetext{
${ }^{50}$ Leff (2004): IX.

${ }^{51}$ Falconí (2014).

${ }^{52}$ Leff (2004): X.
} 
Una racionalidad económica y tecno-científica que, a medida que fue expandiendo su potencia, fue "socavando las bases de sustentabilidad de la vida" ${ }^{\text {. }}$.

En América Latina el desarrollo (o, más bien, el desarrollismo) siempre estuvo íntimamente vinculado a la apropiación intensa y depredadora de los recursos naturales. En Ecuador, el texto constitucional de Montecristi (Constitución de 2008), es un intento muy serio por virar ese rumbo hacia conceptos de desarrollo más sustentables o sostenibles. Bien es verdad, como señala el uruguayo Eduardo Gudynas, que hay nociones débiles de sustentabilidad, que apenas conciben una amortiguación de los efectos más nocivos sobre el medio ambiente, pero sin poner en cuestión la noción misma de "crecimiento económico ilimitado" y el concepto de naturaleza como recurso infinitamente explotable. Un concepto fuere de sustentabilidad, por el contrario, sí pondría en entredicho esas nociones ${ }^{54}$.

Nótese que no sólo se aluden a los "derechos humanos de tercera generación", que incluyen el derecho a un medio ambiente saludable, sino a los derechos intrínsecos de la Naturaleza, de la "Pachamama", más allá de la utilidad que pueda reportar a los humanos. Esto último escapa a las nociones occidentales. En ese sentido, el texto ecuatoriano avanza mucho más que el boliviano (el cual permanece anclado en posiciones aún utilitaristas o neo-extractivistas). La Constitución ecuatoriana no renuncia a la eficiencia económica, pero siempre dentro de los límites biofísicos sustentables (y no, por lo tanto, una "eficiencia" presidida por la lógica de la máxima rentabilidad a cualquier precio). Frente a los valores del productivismo desaforado, la competitividad y el egoísmo de la sociedad capitalista, que promueve que los individuos se instrumentalicen entre sí en un contexto de sociabilidad mermada y debilitada, un nuevo pacto de convivencia inspirado en el Buen vivir ha de implicar una transmutación de dichos valores, imbricando dicha noción con propuestas ecologistas, republicanas e incluso socialistas ${ }^{55}$.

Acosta señalaba en otro trabajo es que la noción de "Buen vivir" surgió en "la periferia social de la periferia mundial" 56 . Es esto muy importante. Semejante concepción, en efecto, surge al calor de las luchas populares y, en especial, de las luchas indígenas. Y quiero ser, antes que un mero reconocimiento constitucional, una nueva forma de vida que suponga una alternativa a los conceptos de

\footnotetext{
${ }^{53}$ Leff (2004): X.

${ }^{54}$ Gudynas (2011).

${ }^{55}$ Ramírez (2010).

${ }^{56}$ Acosta (2011): 61 .
} 
"desarrollo" y "progreso" hasta ahora hegemónicos. Una nueva visión que quiere hacerse desde "la visión de los marginados de la historia" 57 . Esto último, sin duda, aparece muy emparentado con las propuestas de la "filosofía de la liberación" de Enrique Dussel ${ }^{58}$ o Juan Carlos Scannone ${ }^{59}$. Pero también con la Teología de la Liberación y su "opción preferencial por los pobres"

El Sumak Kawsay permite construir una alternativa epistémica al discurso ortodoxo de la teoría económica ortodoxa, una línea de fuga que salga de los límites marcados por el paradigma liberal.

Ante la presencia de la alteridad radical los supuestos de base de la economía moderna no son pertinentes. En las comunidades indígenas no existen individuos que maximizan su comportamiento en función de su egoísmo estratégico. Ese mismo principio de racionalidad estratégica que calcula el mayor beneficio posible de recursos escasos, no tiene ni sentido ni pertinencia en el mundo andino ni en ningún otro estructurado desde las instituciones ancestrales ${ }^{61}$.

Su sola presencia, la subsistencia de formas de vida situadas fuera (o siquiera parcialmente fuera) de la racionalidad capitalista, ponen en cuestión el núcleo ideológico del discurso económico dominante: la perennidad ahistórica de la lógica económica basada en el individualismo competitivo y en la maximización permanente del propio interés ${ }^{62}$. Es por eso que el Sumak Kawsay anclado en los saberes y en las prácticas culturales de estos pueblos puede erigirse en un locus epistémico desde el cual deconstruir todo el armazón conceptual (e ideológico) del discurso económico ortodoxo. Por ello, el Sumak Kawsay permite pensar otro tipo de subjetividades, más allá del homo oeconomicus ${ }^{63}$. Y, por lo mismo, puede

\footnotetext{
${ }^{57}$ Acosta (2011): 62.

${ }^{58}$ Dussel (1985).

${ }^{59}$ Scannone (1990).

${ }^{60}$ Ellacuría (2012).

${ }^{61}$ Dávalos (2011b): 28.

62 Temple (1995); Acosta (2013).

${ }^{63}$ Dávalos (2011a).
} 
también erigirse en un horizonte de sentido que al menos permita imaginar alternativas a la modernización capitalista.

\section{Referencias bibliográficas}

Acosta, A. (2010). El Buen Vivir en el camino del post-desarrollo. Una lectura desde la Constitución de Montecristi. Quito: Fundación Friedrich Ebert, FES-ILDIS.

-(2011). "El Buen Vivir en el camino del post-desarrollo. Algunas reflexiones al andar". En Gabriela Weber (eds.), Debates sobre cooperación y modelos de desarrollo. Perspectivas desde la Sociedad Civil en el Ecuador. Quito: Centro de Investigaciones CIUDAD, Observatorio de la Cooperación al Desarrollo en Ecuador, 61-82.

-(2013). El Buen vivir. Sumak Kawsay, una oportunidad para imaginar otros mundos. Barcelona: Icaria.

Aромеiт, K. (1995). Aristóteles, sobre la amistad. Córdoba: Universidad, Servicio de Publicaciones, D.L.

Aristóteles (2000). Política. Madrid: Gredos.

Aristóteles (2003). Ética a Nicómaco. Madrid: Alianza.

Basañez, F. (1994). "El lugar epistemológico de 'lo económico' en Aristóteles". Themata, No $12,133-170$.

Belotti, F. (2014). "Entre bien común y buen vivir. Afinidades a distancia". Íconos. Revista de Ciencias Sociales, FLACSO, Quito, No 48, 41-54.

BORISONIK, H. (2013). "El debate moderno sobre los escritos económicos aristotélicos". Revista de Economía Institucional, Vol. 15, No 28, Primer Semestre, 183-203.

Chujı, M. (2014). "Modernidad, desarrollo, interculturalidad y Sumak Kawsay o Buen Vivir”. En Hidalgo-Capitán A. L., Guillén A. y Deleg N. (Eds.), Antología del Pensamiento Indigenista Ecuatoriano sobre el Sumak Kausay. Huelva (España) y Cuenca (Ecuador): CIM, FIUCUHU, PYDLOS, Centro de Investigación en Migraciones (CIM), Universidad de Huelva, Universidad de Cuenca, 155-158.

Conill Sancho, J. (2013). Horizontes de economía ética. Aristóteles, Adam Smith, Amartya Sen. Madrid: Tecnos.

Cubillo, A. P.; HidAlgo, A. L. (2015). "El Sumak Kawsay genuino como fenómeno social amazónico ecuatoriano". OBETS. Revista de Ciencias Sociales, Vol. 10, № 2 , 301-333.

DALE, G. (2010). Karl Polanyi: the limits of the market. Cambridge: Polity.

Dalton, G. (1974). Sistemas económicos y sociedad. Madrid: Alianza. 
Dávalos, P. (2011a). "La necesidad de un nuevo paradigma en la economía. ¿Puede la noción de Sumak Kawsay ser la alternativa?”. Polémika. Revista del Instituto de Economía de la Universidad San Francisco de Quito, Año 2, № 6, marzo, 32-46.

-(2011b). "El Sumak Kawsay (Buen Vivir) y la crítica a la teoría económica como ideología". Polémika. Revista del Instituto de Economía de la Universidad San Francisco de Quito, Año 3, No 7, junio, 17-31.

Dumont, L. (1999). Homo aequalis. Génesis y apogeo de la ideología económica. Madrid: Taurus.

Dussel, E. (1985). Filosofia de la liberación. Buenos Aires: La Aurora.

Ellacuría, I. (2012). La lucha por la justicia. Selección de textos de Ignacio Ellacuría (1969-1989). Bilbao: Universidad de Deusto.

Falconí, F. (2014). Al sur de las decisiones. Enfrentando la crisis del siglo XXI. Quito: El Conejo.

Foucault, M. (2009). Nacimiento de la biopolitica. Curso del Collège de France (19781979). Madrid: Akal.

Fromm, E. (1985). Ética y psicoanálisis. Madrid: Fondo de Cultura Económica.

GaUthieR, D. (1994). La moral por acuerdo. Barcelona: Gedisa.

Gorz, A. (1997). Metamorfosis del trabajo; buisqueda del sentido; crítica de la razón económica. Madrid: Sistema.

Gudynas, E. (2010). "La ecología política de la crisis global y los límites del capitalismo benévolo". Íconos. Revista de Ciencias Sociales (FLACSO), No 36, 53-67.

-(2011). "Desarrollo, Derechos de la Naturaleza y Buen Vivir después de Montecristi". En Gabriela Weber (eds.), Debates sobre cooperación y modelos de desarrollo. Perspectivas desde la Sociedad Civil en el Ecuador. Quito: Centro de Investigaciones CIUDAD, Observatorio de la Cooperación al Desarrollo en Ecuador, 83-102.

Hidalgo, A. L., Arias, A. y Ávila, J. (2014). "El pensamiento indigenista ecuatoriano sobre el Sumak Kawsay”. En Hidalgo-Capitán A. L., Guillén A. y Deleg N. (eds.), Antologia del Pensamiento Indigenista Ecuatoriano sobre el Sumak Kawsay. Huelva (España) y Cuenca (Ecuador): CIM, FIUCUHU, PYDLOS, Centro de Investigación en Migraciones (CIM), Universidad de Huelva, Universidad de Cuenca, 29-73.

LaClau, E. (2013). La razón populista. México: Fondo de Cultura Económica.

Lafargue, P. (1998). El derecho a la pereza. Madrid: Fundamentos.

Laski, H. J. (1953). El liberalismo europeo. México: Fondo de Cultura Económica.

LefF, E. (2004). Racionalidad ambiental. La reapropiación social de la naturaleza. México: Siglo Veintiuno. 
Manosalvas, M. (2014). "Buen vivir o sumak kawsay. En busca de nuevos referenciales para la acción pública en Ecuador”. Íconos. Revista de Ciencias Sociales (FLACSO), No 49, 101-121.

Medina, J. (2001). Suma Qamaña. La comprensión indigena de la Vida Buena. La Paz: GTZ-PADEP.

Mingione, E. (1994). Las sociedades fragmentadas. Una sociología de la vida económica más allá del paradigma del mercado. Madrid: Ministerio de Trabajo y Seguridad Social.

Moulier-Boutang, Y. (2006). De la esclavitud al trabajo asalariado. Economía histórica del trabajo asalariado embridado. Madrid: Akal.

Nussbaum, M. C. (1992), "Human Functioning and Social Justice: In Defense of Aristotelian Essentialism", Political Theory, Vol. 20 (2), pp. 202-246.

Polanyi, K. (1976a). "Aristóteles descubre la economía". En Comercio y mercado en los imperios antiguos. Barcelona: Labor.

-(1976b). "El lugar de la economía en la sociedad". En Comercio y mercado en los imperios antiguos. Barcelona: Labor.

-(1991). "Sobre la fe en el determinismo económico". Archipiélago. Cuadernos de crítica de la cultura, Madrid, No 8, 72-80.

-(1994a). El sustento del hombre. Barcelona: Mondadori.

-(1994b). "Nuestra obsoleta mentalidad de mercado". Cuadernos de Economía, Universidad Nacional de Colombia, Vol. 14, No 20, 249-266.

(2003). La gran transformación. Los orígenes politicos y económicos de nuestro tiempo. México: Fondo de Cultura Económica.

(2014). "El eclipse del pánico y las perspectivas del socialismo". En César Rendueles (eds.), Los límites del mercado. Reflexiones sobre economía, antropología y democracia. Madrid: Capitán Swing.

Polo Blanco, J. (2014). "Los mitos del interés propio universal y la razón eternamente calculadora". Factótum. Revista de Filosofía, Universidad de Salamanca, No 12, 47-62.

-(2015). “También explotación, pero no sólo. Un diálogo imprescindible y polémico entre Marx y Karl Polanyi”. Tópicos. Revista de Filosofía, Universidad Panamericana, México, No 49, 81-121.

-(2016). "Secularizando la sacrosanta economía. Hacia una crítica del «imperialismo de lo económico» en el ámbito de las ciencias sociales", Disertaciones, Universidad del Quindío, Armenia, Colombia, Vol. 5, No 1, 18-37. 
Ramírez, R. (2010). "Socialismo del sumak kawsay o biosocialismo republicano". En Los nuevos retos de América Latina. Socialismo y sumak kawsay, Quito: SENPLADES, 55-76.

Sahlins, M. (1977). Economía de la edad de piedra. Madrid: Akal.

Scannone, J. C. (1990). Nuevo punto de partida en la filosofia latinoamericana. Buenos Aires: Guadalupe.

Simmel, G. (2003). Filosofía del dinero. Granada: Comares.

SOMBART, W. (1972). El burgués. Contribución a la historia espiritual del hombre económico moderno Madrid: Alianza.

Spranger, E. (1988). Formas de vida. Psicología y ética de la personalidad. Madrid: Revista de Occidente.

Tawney, R. H. (1972). La sociedad adquisitiva. Madrid: Alianza.

Temple, D. (1995). La dialéctica del don. Ensayo sobre la oikonomía de las comunidades indigenas. La Paz: Hisbol.

Thompson, E. P. (1995). Costumbres en común. Barcelona: Crítica.

Vega, F. (2014). "El Buen vivir-Sumak Kawsay en la Constitución y en el PNBV 20132017 del Ecuador”. OBETS. Revista de Ciencias Sociales, Vol. 9, No 1, 167-194.

Viola ReCasens, A. (2014). "Discursos 'pachamamistas' versus políticas desarrollistas: el debate sobre el sumak kawsay en los Andes". Íconos. Revista de Ciencias Sociales (FLACSO), No 48, 55-72.

Walsh, C. (2009). "Interculturalidad, decolonialidad y el buen vivir", en Interculturalidad, Estado, sociedad. Luchas (de) coloniales de nuestra época. Quito: Universidad Andina Simón Bolívar, Ediciones Abya-Yala, 213-235.

Weber, M. (2003). La ética protestante y el "espiritu" del capitalismo. Madrid: Alianza.

Zuberman, F. (2013). "El aporte del pensamiento de Karl Polanyi a la cuestión ambiental". Revibec. Revista de la Red Iberoamericana de Economía Ecológica, Vol. 21, 57-70.

Recibido : 29/11/2016

Aceptado : 17/01/2017

\section{@() $\Theta \Theta$}

ENDOXA está bajo una licencia de Creative Commons Reconocimiento-NoComercial-SinObraDerivada 4.0 Internacional 